benefit from hospital admission for selected patients with suspected myocardial infarction and where diagnostic or therapeutic help in the home was offered, home care did not make any substantial impact on the need for hospital services.

If general practitioners do not consider home care to be an acceptable form of management for patients with suspected myocardial infarction, then there is little point in their playing any part when patients develop suspicious symptoms. In fact, general practitioners cannot help most patients who die from a heart attack: a register of all patients with heart attacks in the Nottingham Health District confirmed earlier reports that most deaths occur soon after the onset of symptoms and before medical aid is sought. ${ }^{78}$ If virtually all patients with heart attacks who survive long enough are going to be admitted to hospital, should the general practitioners and patients be persuaded that a call for an emergency ambulance is the appropriate action and not a call for a general practitioner? There is, however, little point in instituting such a programme of public education without an ambulance that can respond appropriately. After two of our earlier studies had shown that a single "coronary" ambulance could not be used effectively, ${ }^{910}$ the emergency and routine functions of our ambulance service were separated, and all the emergency vehicles are now being equipped with defibrillators and their crews specially trained. A programme of community education in the need to call for an emergency ambulance rather than a general practitioner together with public education in cardiopulmonary resuscitation is now beginning, and we shall use our heart attack register to monitor its effect.

We gratefully acknowledge the help given to us by the general practitioners, senior house officers, and coronary care unit nurses, and we are indebted to G D Searle \& Company Limited for financial support. The study could not have been completed without the willing cooperation of the health authorities and ambulance service.

\section{References \\ 'Fulton $M$, Julian DG, Oliver MF. Sudden death and myocardial infarction. Circulation 1969;40,suppl 4:182-93. \\ Hill JD, Hampton JR. Mode of referral to hospital of patients with heart attacks: relevance to home care and special ambulance services. Br Med $\mathcal{f}$ 1976;ii:1035-6. Mather HG, Pearson NG, Read KLQ, et al. Acute myocardial infarction: home and hospital treatment. $B r$ Med $\mathcal{f} 1971$;iii:334-8. \\ mised trial of home-versus-hospital management for patients with suspected myocardial infarction. Lancet 1978; $\mathrm{i}$ : \\ - Colling A Dellipiani AW, Donaldson RJ, MacCormack P Teesside coronary sur- vey: an epidemiological study of acute attacks of myocardial infarction. Br Med vey: an epidemiolo \\ ' Rowley JM, Hill JD, Hampton JR, Mitchell JRA. Early reporting of myocardial infarction: impact of an experiment in patient education. $\mathrm{Br}$ Med $\mathcal{F} 1982 ; 284$ : $1741-5$ \\ Kinlen LJ. Incidence and presentation of myocardial infarction in an English community. Br Heart $\mathcal{F} 1973 ; 35$ :616-22. \\ Pedoe HT. Uses of coronary heart attack registers. Br Heart 7 1978;40:510-5. \\ Hampton JR. Importance of patient selection in evaluating a cardiac ambulance service. Br Med f 1976; ; :201-4. Hampton JR, Nicholas C. Randomised trial of a mobile coronary care unit for
emergency calls. Br Med $\mathcal{f} 1978 ; \mathrm{i}: 1118-21$. \\ (Accepted 17 May 1984)}

\title{
$\beta$ Blockade, diuretics, and salt restriction for the management of mild hypertension: a randomised double blind trial
}

\author{
T M ERWTEMAN, N NAGELKERKE，J LUBSEN，M KOSTER，A J DUNNING
}

\begin{abstract}
Ninety four patients with mild hypertension (average supine diastolic blood pressure (phase V) 95-110 $\mathrm{mm} \mathrm{Hg}$ ) were allocated at random to receive restriction of dietary sodium (maximum allowed $70 \mathrm{mmol}(\mathrm{mEq}) /$ $24 \mathrm{~h}$ ) or a normal diet. In addition, they received in random order $25 \mathrm{mg}$ chlorthalidone, $200 \mathrm{mg}$ metoprolol (slow release), and a fixed combination of these two drugs. Each drug treatment was given for four weeks and alternated with four weeks of placebo. Forty four patients were allocated to sodium restriction (group 1) and 50 to normal diet (group 2).
\end{abstract}

The mean 24 hour urinary sodium excretion in group 1

\footnotetext{
Department of Internal Medicine, Academisch Medisch Centrum Amsterdam, The Netherlands

TH M ERWTEMAN, MD, PHD, consultant physician, hypertension clinic $M$ KOSTER, MD, PHD, professor of internal medicine

A J DUNNING, MD, PHD, professor of cardiology

Department of Medical Statistics, University of Amsterdam N NAGELKERKE, MSC, PHD, statistician
}

Thorax Centrum, Academic Hospital of the University of Rotterdam J LUBSEN, MD, PHD, head of clinical epidemiology

Correspondence to: Dr Th M Erwteman, Academisch Medisch Centrum, Department of Internal Medicine, Hypertension Clinic, Meibergdreef 9 , 1105 AZ Amsterdam-ZO, The Netherlands. was 74 (SD 31) mmol(mEq)/24 h, and in group 2132 (51) mmol/24 h. Compared with the screening blood pressure the average decrement of the supine blood pressure in group 1 was $16.0 / 8.6 \mathrm{~mm} \mathrm{Hg}$ with placebo, $21.7 / 11.5$ $\mathrm{mm} \mathrm{Hg}$ with the diuretic, $28.5 / 17.8 \mathrm{~mm} \mathrm{Hg}$ with the $\beta$ blocker, and $28.9 / 18.4 \mathrm{~mm} \mathrm{Hg}$ with the combined agent; in group 2 these values were 13.3/6.1, 20.3/9.7, 21.3/12.9, and $29 \cdot 4 / 16.8 \mathrm{~mm} \mathrm{Hg}$, respectively. There was a sharp decrease of the average potassium concentration during chlorthalidone and combination treatment periods (average value $3.3 \mathrm{mmol}(\mathrm{mEq}) / \mathbf{l})$.

These results suggest that moderate salt restriction used as sole treatment has a limited though demonstrable blood pressure lowering effect but that when it is used as an adjuvant to $\beta$ blocker treatment its value is greatly enhanced.

\section{Introduction}

An abundance of therapeutic options is now available for mild hypertension, but the treatment of choice-that is, one combining maximal efficacy with minimal side effects-is still a matter of dispute. This often centres on whether to use $\beta$ blockers or diuretics as the first line of treatment. Adverse reactions may occur with either of these treatments, ${ }^{1}$ however, so that some workers favour a non-pharmaceutical approach to symptomless, mild hypertension, such as restriction of the daily sodium intake. While the effctiveness of severe sodium restriction (less than $20 \mathrm{mmol}(\mathrm{mEq}) / 24 \mathrm{~h}$ ) has been recognised for over 35 years $^{2}$ the 
results of clinical trials aimed at proving the efficacy of moderate sodium restriction for raised blood pressure remain conflicting.

Parijs et al found a significant fall in blood pressure only when measured in the morning. ${ }^{3}$ Simpson and Swales received earlier trials and commented that the evidence was too weak to recommend moderate salt restriction as a general first measure for raised blood pressure. ${ }^{45}$ Andrews et al compared 37 reports of trials of drug and non-drug treatments of raised blood pressure and concluded that salt restriction achieved less than weight reduction, yoga, and muscle relaxation. ${ }^{6}$ Watt and Silman, in independent studies, found no benefit for salt restriction over a general health package for blood pressure lowering effect. ${ }^{7}$ By contrast, MacGregor et al reported a significant decrease in the average blood pressure of 19 mild hypertensives treated with a diet containing $60-80 \mathrm{mmol}$ sodium $/ 24 \mathrm{~h} .{ }^{9}$ Results of studies that combined drug treatment with sodium restriction were equally inconclusive. In the same study Parijs et al found a significant decrease of the blood pressure on all occasions when hydrochlorothiazide was added to the sodium restricted diet. Conversely, van Brummelen et al found no further lowering of the blood pressure when hydrochlorothiazide treated hypertensives restricted their sodium consumption to $50 \mathrm{mmol} / 24 \mathrm{~h} .^{10}$

We decided to investigate the hypotensive effects of a slow release preparation of the $\beta$ blocker metoprolol (200 mg daily), of the diuretic chlorthalidone (25 mg daily), and of a fixed combination of these two agents. The study was carried out as a randomised, crossover, double blind clinical trial with intervening placebo periods in which the drug regimens were compared. In addition, we studied the effects of moderate salt restriction (maximum allowed $70 \mathrm{mmol}$ sodium $/ 24 \mathrm{~h}$ ) by separating the patients into two subgroups with different salt intakes. The study comprised 107 mild hypertensives and was carried out in one centre by a working committee of one physician in charge, a technician specially trained in blood pressure measurement, a dietitian, and a statistician.

\section{Patients and methods}

Patients were eligible for the study if they met all of the following criteria: (1) age 20-70 years; (2) supine diastolic blood pressure (disappearance of sounds) $95-110 \mathrm{~mm} \mathrm{Hg}$ on two different occasions; (3) no history of chronic obstructive pulmonary disease, asthma, gout, diabetes mellitus, or accelerated hypertension; (4) in patients under 40 , normal iodine-131-Hippuran renogram; (5) not receiving hypertensive treatment or, if treated, treatment discontinued at least three weeks before the study; (6) no known idiosyncratic reactions to any of the drugs under investigation; (7) plasma creatinine concentration less than $200 \mu \mathrm{mol} / 1(2.3 \mathrm{mg} / 100 \mathrm{ml})$; (8) no evidence of coronary insufficiency, heart failure, conduction disturbances, or ventricular aneurysm; (9) not taking oral contraceptives; (10) not pregnant.

At entry the patients underwent a full physical examination by the physician in charge. Blood pressure was measured with a Hawksley random zero sphygmomanometer ${ }^{11}$ by the technician after 10 minutes rest supine and again after two minutes of standing. Blood samples were then drawn for haematological and biochemical analysis (electrolyte concentrations, liver and kidney function values, glucose, lipid, and urate concentrations). Plasma renin activity was determined both standing and supine. For the analysis the average was used. The 24 hour urinary excretion of vanillylmandelic acid was determined and a urine sample analysed. All patients underwent fundoscopy by an ophthalmologist and had their electrocardiograms and chest $x$ ray pictures evaluated by a cardiologist and radiologist, respectively, who were not aware of the patients' condition. $\mathbf{A}^{131}$ I-Hippuran renogram was made in all patients under 40 . Other investigations were done only when clinically indicated. Written, informed consent was obtained in all cases. Patients were entered into the study from June 1979 until
April 1981.

Treatment regimens-Eligible patients were allocated at random to receive either a normal or a sodium restricted diet. In addition, each patient was randomly assigned to one of the drug treatment orders shown in table I. All assignments were balanced in blocks of 24 . Assignment to diet was single blind; both dietary groups were supervised by the dietitian, who instructed the patients in their assigned diets and asked them not to discuss these with the physician in charge or the technician. Drug assignment was strictly double blind.
TABLE I-Orders of drug treatment

\begin{tabular}{cclllll}
\hline & \multicolumn{7}{c}{ Treatment period (each of 4 weeks) } \\
\cline { 2 - 7 } $\begin{array}{c}\text { Treatment } \\
\text { order No }\end{array}$ & $\mathbf{1}$ & $\mathbf{2}$ & $\mathbf{3}$ & $\mathbf{4}$ & $\mathbf{5}$ & $\mathbf{6}$ \\
\hline $\mathbf{1}$ & $\mathbf{P}$ & $\mathbf{B}$ & $\mathbf{P}$ & $\mathbf{D}$ & $\mathbf{P}$ & $\mathbf{C}$ \\
2 & $\mathbf{B}$ & $\mathbf{P}$ & $\mathbf{D}$ & $\mathbf{P}$ & $\mathbf{C}$ & $\mathbf{P}$ \\
$\mathbf{3}$ & $\mathbf{P}$ & $\mathbf{D}$ & $\mathbf{P}$ & $\mathbf{B}$ & $\mathbf{P}$ & $\mathbf{C}$ \\
$\mathbf{4}$ & $\mathbf{D}$ & $\mathbf{P}$ & $\mathbf{B}$ & $\mathbf{P}$ & $\mathbf{C}$ & $\mathbf{P}$ \\
6 & $\mathbf{P}$ & $\mathbf{D}$ & $\mathbf{P}$ & $\mathbf{C}$ & $\mathbf{P}$ & $\mathbf{B}$ \\
7 & $\mathbf{P}$ & $\mathbf{P}$ & $\mathbf{C}$ & $\mathbf{P}$ & $\mathbf{B}$ & $\mathbf{P}$ \\
$\mathbf{8}$ & $\mathbf{P}$ & $\mathbf{P}$ & $\mathbf{P}$ & $\mathbf{C}$ & $\mathbf{P}$ & $\mathbf{D}$ \\
$\mathbf{9}$ & $\mathbf{P}$ & $\mathbf{C}$ & $\mathbf{P}$ & $\mathbf{P}$ & $\mathbf{D}$ & $\mathbf{P}$ \\
10 & $\mathbf{C}$ & $\mathbf{P}$ & $\mathbf{D}$ & $\mathbf{P}$ & $\mathbf{P}$ & $\mathbf{B}$ \\
11 & $\mathbf{P}$ & $\mathbf{C}$ & $\mathbf{P}$ & $\mathbf{B}$ & $\mathbf{P}$ & $\mathbf{P}$ \\
12 & $\mathbf{C}$ & $\mathbf{P}$ & $\mathbf{B}$ & $\mathbf{P}$ & $\mathbf{D}$ & $\mathbf{P}$ \\
\hline
\end{tabular}

$\mathrm{P}=$ Placebo. $\mathrm{D}=$ Chlorthalidone $25 \mathrm{mg} . \mathrm{B}=$ Metoprolol $200 \mathrm{mg}$, slow release. $\mathrm{C}=$ Fixed combination of chlorthalidone and metoprolol.

Follow up-At the beginning of the first treatment period the first bottle of pills was handed out. Each active drug was given for four weeks and alternated with four weeks of placebo, so that the observation period for each patient lasted 24 weeks. Patients were seen at weekly intervals, on the same day of the week and at the same time. Blood pressure was taken as described above, by the same technician. At each visit side effects were sought by general questioning and the remaining pills counted. Patients were instructed to collect a 24 hour urine sample once a week. The 24 hour urinary sodium excretion was determined and reported to the dietitian only, who then discussed compliance and the dietary instructions. Every fourth week the patient was also seen by the physician in charge. A new bottle of pills was handed out, blood samples drawn for plasma determinations of glucose, sodium, potassium, creatinine, cholesterol, and urate, and a urine sample analysed. If a patient missed more than two visits or the last visit of a period, or both, the trial was extended by this period without breaking the code. The trial was discontinued if serious medical complications developed.

Closedown procedure - At the end of the trial the medication that had yielded the lowest average diastolic blood pressure was continued without breaking the code.

Statistical analysis-To minimise carry over effects we used only the last blood pressure reading of all three placebo periods. The average of these readings was compared with the average of the last three readings of each active treatment period. Readings during the first week of an active treatment period were discarded, since drugs may need time to exert a hypotensive effect. The significance of differences in average blood pressures between the time of screening and during the placebo and each of the active treatment periods was tested simultaneously by Duncan's multiple range test. ${ }^{12}$ The effect of salt restriction-that is, a between group comparison of the differences in falls in blood pressure after screening between the dietary groups-was examined by $t$ tests and associated one sided $\mathrm{p}$ values.

\section{Results}

Of the toral of 107 patients, 13 failed to complete the study: eight were withdrawn because they missed three consecutive visits without making alternative arrangements; one was prescribed an oral contraceptive; one was admitted to hospital for a gynaecological procedure; one had a stroke (not fatal); one had progressive angina pectoris; and one died of a dissecting aneurysm. There was no apparent relation between treatment, blood pressure, and discontinuing the trial. These patients are excluded from the analysis. Table II shows the baseline characteristics of the remaining 94 patients. Of these, 44 were assigned to receive the sodium restricted diet and 50 to take the normal diet.

Compliance-Patient compliance was satisfactory: 62 of the 94 patients missed at most two visits, 30 missed three to seven visits, and two patients missed more than seven visits. Of the prescribed intake of 168 tablets, 85 of the patients omitted fewer than 10 , seven omitted 11-20, and only two omitted 21-30 tablets. Although some patients did not adhere precisely to the instructions about collecting their 24 hour urine sample once a week (judging from the changing volumes and changing 24 hour creatinine excretion), a significant $(p<0.05)$ difference in salt excretion was found between the two dietary groups (table III).

Blood pressure - In all treatment orders there was a substantial fall in blood pressure between the screening period and the first treatment period. After this initial drop there was no further time trend. In both dietary groups the lowest blood pressures were found during treatment with the combination pill, followed by the $\beta$ blocker, the diuretic, and 
TABLE II-Baseline characteristics of subjects studied (mean values are expressed with $S D$ in parentheses)

\begin{tabular}{|c|c|c|}
\hline & $\begin{array}{l}\text { Sodium restricted diet } \\
(\mathrm{n}=44)\end{array}$ & $\begin{array}{l}\text { Normal diet } \\
\quad(\mathrm{n}=50)\end{array}$ \\
\hline \multicolumn{3}{|l|}{ Supine diastolic blood pressure } \\
\hline Age (years) & $\begin{array}{r}101 \cdot 0(5 \cdot 4) \\
45 \cdot 0(11 \cdot 0)\end{array}$ & $\begin{array}{r}100 \cdot 5(3.4) \\
46 \cdot 5(9 \cdot 5)\end{array}$ \\
\hline $\begin{array}{l}\text { White } \\
\text { Male }\end{array}$ & $77^{\circ} \circ$ & $76 \%$ \\
\hline $\begin{array}{l}\text { Male } \\
\text { Smoked > } 10 \text { cigarettes } / \text { day }\end{array}$ & $\begin{array}{l}61 \% \\
30\end{array}$ & $62 \%$ \\
\hline Took $>2$ alcoholic drinks/day & $32 \%$ & $22 \%$ \\
\hline More than $10^{\circ} \%$ overweight & $59 \%$ & $42 \%$ \\
\hline $\begin{array}{l}\text { Cholesterol }(\mathrm{mmol} / \mathrm{l}) \\
\text { Glucose }(\mathrm{mmol} / \mathrm{l})\end{array}$ & $\begin{array}{l}6 \cdot 3(1 \cdot 1) \\
5 \cdot 3(0 \cdot 8)\end{array}$ & $\begin{array}{l}6.4(1 \cdot 2) \\
5 \cdot 1(0 \cdot 7)\end{array}$ \\
\hline Urate $(\mathrm{mmol} / \mathrm{l})$ & $0.34(0.08)$ & $0.34(0.07)$ \\
\hline Plasma renin activity $(\mu \mathrm{g} / \mathrm{l})$ & $1.63(1 \cdot 1)$ & $1.63(1 \cdot 1)$ \\
\hline Creatinine $(\mu \mathrm{mol} / \mathrm{l})$ & $81(15)$ & $81(13)$ \\
\hline Left ventricular hypertrophy ${ }^{\dagger}$ & $13^{\circ}$ & $18 \%$ \\
\hline $\begin{array}{l}\text { Cardiothoracic ratio } \\
\text { Hypertensive retinopathy }\end{array}$ & $0.47(0.03)$ & $0.47(0.04)$ \\
\hline $\begin{array}{l}\text { Grade } 1 \\
\text { Grade } 2\end{array}$ & $\begin{array}{l}30 \% \\
16 \%\end{array}$ & $\begin{array}{l}28^{\circ} \\
14^{\circ} \circ\end{array}$ \\
\hline
\end{tabular}

* Tables Nederlandse Hart Stichting.

$\dagger$ By electrocardiographic criteria.

† Keigh-Wagener criteria

Conversion: SI to traditional units-Cholesterol: $1 \mathrm{mmol} / 1 \approx 38.6 \mathrm{mg} / 100 \mathrm{ml}$ $1 \mu \mathrm{mol} / \mathrm{l} \approx 0.01 \mathrm{mg} / 100 \mathrm{ml}$.

TABLE III-Twenty four hour urinary sodium excretion ( $m m o l(m E q)$ ) during the various treatment periods. Values are mean ( $S D$ in parentheses)

\begin{tabular}{lrrrrr}
\hline & Placebo & $\beta$ Blocker & Diuretic & Combination All patients \\
\hline $\begin{array}{l}\text { Sodium restricted diet } \\
(\mathrm{n}=44)\end{array}$ & $72(31)$ & $74(32)$ & $79(32)$ & $74(27)$ & $74(31)$ \\
Normal diet $(\mathrm{n}=50)$ & $130(50)$ & $129(51)$ & $140(54)$ & $132(50)$ & $132(41)$ \\
\hline
\end{tabular}

blocker and diuretic treatment we plotted the differences in blood pressure between the metoprolol and chlorthalidone treatment periods against both age and screening plasma renin value. Figures 1 and 2 show the plots for supine diastolic blood pressure. Corresponding results were found for the other blood pressure measurements. There was no clear correlation between age and plasma renin activity. Consequently these two effects were independent, which was confirmed by multiple regression analysis.

Tolerance-All drug treatments were tolerated equally well. Nonspecific complaints and possible side effects were infrequent and reported during all treatment periods (table VI).

TABLE VI-Side effects reported during the three placebo periods together and the three "active" treatment periods. (Figures are numbers of subjects)

\begin{tabular}{lcccc}
\hline & Placebo & Chlorthalidone & Metoprolol & Combination \\
\hline Fatigue, heavy legs & 11 & 6 & 10 & 10 \\
Decreased potency & & 1 & 1 & \\
Arthralgia & 1 & 5 & & \\
Cough, dyspnoea & 8 & 6 & 9 & 6 \\
Headache & 11 & 2 & 3 & 5 \\
Lightheadedness & 3 & 1 & 1 & 4 \\
Gastrointestinal disturbance & 4 & 1 & & \\
$\begin{array}{l}\text { Cold hands and feet } \\
\text { Swollen feet }\end{array}$ & 1 & 1 & 3 & 1 \\
Vivid dreams & 1 & 1 & & \\
Profuse sweating & & &
\end{tabular}

Biochemical analysis - There was a sharp fall in the serum potassium concentration during chlorthalidone and combination treatment (table VII). Ten patients $(23 \%)$ taking the low sodium diet and $8(16 \%)$ taking the normal diet had a plasma potassium concentration below

TABLE IV-Supine and standing systolic and diastolic blood pressures ( $\mathrm{mm} \mathrm{Hg}$ ) recorded during screening and during treatment with placebo, diuretic, $\beta$ blocker, and combination pills with and without salt restriction. Values are means ( $S D$ in parentheses)

\begin{tabular}{|c|c|c|c|c|c|c|c|c|}
\hline & \multicolumn{4}{|c|}{ Salt restricted diet $(n=44)$} & \multicolumn{4}{|c|}{ Normal diet $(n=50)$} \\
\hline & \multicolumn{2}{|c|}{ Systolic } & \multicolumn{2}{|c|}{ Diastolic } & \multicolumn{2}{|c|}{ Systolic } & \multicolumn{2}{|c|}{ Diastolic } \\
\hline & Supine & Standing & Supine & Standing & Supine & Standing & Supine & Standing \\
\hline $\begin{array}{l}\text { Screening } \\
\text { Placebo } \\
\text { Chlorthalidone } \\
\text { Metoprolol } \\
\text { Combination }\end{array}$ & $\begin{array}{l}157.0(11.4) \\
141.0(15.4) \\
135.3(14.8) \\
128.5(16.3) \\
128.1(15.0)\end{array}$ & $\begin{array}{l}153.5(12.2) \\
138.3(16.2) \\
131.4(15.8) \\
125.7(16.3) \\
122.1(14.5)\end{array}$ & $\begin{array}{c}101.5(5.4) \\
92.9(10.4) \\
90.5(9.7) \\
83.7(8.6) \\
83.1(9.6)\end{array}$ & $\begin{array}{c}105 \cdot 1(5 \cdot 2) \\
98 \cdot 3(9 \cdot 9) \\
95 \cdot 5(9 \cdot 6) \\
88 \cdot 7(10 \cdot 2) \\
87 \cdot 7(8 \cdot 9)\end{array}$ & $\begin{array}{l}156.2(11.8) \\
142.9(16.4) \\
137.0(13.6) \\
134.6(15.9) \\
126.8(11.6)\end{array}$ & $\begin{array}{l}153.2(11.0) \\
142.6(17.9) \\
132.9(14.6) \\
131.9(17.5) \\
124.7(13.5)\end{array}$ & $\begin{array}{c}100 \cdot 5(3.4) \\
94.4(12 \cdot 0) \\
90 \cdot 8(6 \cdot 9) \\
87.6(9 \cdot 1) \\
83.7(7 \cdot 5)\end{array}$ & $\begin{array}{c}104 \cdot 5(5 \cdot 2) \\
98 \cdot 9(11 \cdot 7) \\
96 \cdot 6(9 \cdot 6) \\
91 \cdot 9(9 \cdot 8) \\
87 \cdot 7(8 \cdot 8)\end{array}$ \\
\hline
\end{tabular}

TABLE $\mathrm{v}-$ Mean differences in fall in blood pressure $(\mathrm{mm} \mathrm{Hg})$ between taking normal and sodium restricted diets during treat ment with placebo, chlorthalidone, metoprolol, and combination. (SEM in parentheses.) [One sided p values in square brackets]

\begin{tabular}{|c|c|c|c|c|}
\hline & \multicolumn{2}{|c|}{ Systolic } & \multicolumn{2}{|c|}{ Diastolic } \\
\hline & Supine & Standing & Supine & Standing \\
\hline $\begin{array}{l}\left(S_{1}-P_{1}\right)-\left(S_{2}-P_{2}\right) \\
\left(S_{1}-D_{1}\right)-\left(S_{2}-D_{2}\right) \\
\left(S_{1}-B_{1}\right)-\left(S_{2}-B_{2}\right) \\
\left(S_{1}-C_{1}\right)-\left(S_{2}-C_{2}\right)\end{array}$ & $\begin{array}{c}2.7(2 \cdot 2)[\mathrm{p}=0.12] \\
2 \cdot 4(2 \cdot 8)[\mathrm{p}=0.02] \\
7 \cdot 23(3 \cdot 0)[\mathrm{p}=0.008] \\
-0.55(2 \cdot 8)[\mathrm{p}=0.42]\end{array}$ & $\begin{array}{l}4.4(2 \cdot 3)[p=0.025] \\
1.8(2 \cdot 8)[p=0.26] \\
6.43(2 \cdot 9)[p=0.015] \\
2 \cdot 83(2 \cdot 7)[p=0.15]\end{array}$ & $\begin{array}{l}3.4(1.7)[\mathrm{p}=0.025] \\
2.07(1.8)[\mathrm{p}=0.13] \\
5.65(1.9)[\mathrm{p}=0.0015] \\
2.40(1.92)[\mathrm{p}=0.11]\end{array}$ & $\begin{array}{l}1.0(1 \cdot 6)[\mathrm{p}=0 \cdot 25] \\
1.63(2 \cdot 0)[\mathrm{p}=0 \cdot 2] \\
3.68(2 \cdot 0)[\mathrm{p}=0.03] \\
0.53(2 \cdot 0)[\mathrm{p}=0.39]\end{array}$ \\
\hline \multicolumn{3}{|c|}{$\begin{array}{l}\mathbf{S}_{2}=\text { Screening blood pressure in normal diet group. } \\
\mathbf{P}_{2}=\text { Mean placebo blood pressure in normal diet group. } \\
\mathrm{D}_{2}=\text { Mean chlorthalidone blood pressure in normal diet group. } \\
\mathbf{B}_{2}=\text { Mean metoprolol blood pressure in normal diet group. } \\
\mathrm{C}_{2}=\text { Mean combination blood pressure in normal diet group. }\end{array}$} & $\begin{array}{l}\text { pressure in sodium } \\
\text { lood pressure in sodi } \\
\text { done blood pressure i } \\
\text { ol blood pressure in s } \\
\text { ion blood pressure in }\end{array}$ & $\begin{array}{l}\text { icted group. } \\
\text { estricted group. } \\
\text { lium restricted group. } \\
\text { m restricted group. } \\
\text { ium restricted group. }\end{array}$ \\
\hline
\end{tabular}

the placebo (table IV). In the salt restricted group the differences were significant ( $p<0.05$; Duncan's multiple range test), except for that between the diuretic and placebo supine diastolic blood pressures and that between the combination pill and the $\beta$ blocker for all blood pressures. With the normal diet there was no statistically significant difference between the diuretic and placebo standing diastolic blood pressures or between the diuretic and $\beta$ blocker supine or standing systolic blood pressures. All other blood pressure differences were significant. The fall in blood pressure after screening during either the placebo or active drug treatment period was consistently larger with salt restriction than with the normal diet (except for supine systolic blood pressure during treatment with the combination pill; table V). The largest differences were found during $\beta$ blocker treatment.

Age, plasma renin activity, and effect of treatment-To study the relation of age and plasma renin activity to the respective effects of $\beta$
$3.0 \mathrm{mmol}(\mathrm{mEq}) / 1$ when receiving chlorthalidone either alone or in combination with metoprolol. In addition, there was a significant increase in urate concentration during chlorthalidone containing treatments. There was no relevant change of glucose, total cholesterol, or high density lipoprotein cholesterol during any treatment period.

\section{Discussion}

The fall in blood pressure in the placebo periods compared with the screening period was considerable. This may be explained by a combination of phenomena such as regression towards the mean, pressor effects, and true placebo effects. ${ }^{13}$ The effect of the diet as sole treatment or in combination with the 
TABLE VII-Biochemical values at end of each treatment period. Values are means (SD in parenthescs)

\begin{tabular}{|c|c|c|c|c|c|c|c|}
\hline & $\mathrm{Na}(\mathrm{mmol} / \mathrm{l})$ & $\mathrm{K}(\mathrm{mmol} / \mathrm{l})$ & Creatinine ( $\mu \mathrm{mol} 1)$ & Urate $(\mathrm{mmol} / \mathrm{l})$ & Cholesterol (mmol/l) & HDL cholesterol $(\mathrm{mmol} / \mathrm{l}) \dagger$ & Glucose (mmol/l) \\
\hline $\begin{array}{l}\text { Placebo }+ \\
\text { Metoprolol } \\
\text { Chlorthalidone } \\
\text { Combination }\end{array}$ & $\begin{array}{l}138(1.9) \\
140(2.0) \\
139(2.0) \\
138(2.0)\end{array}$ & $\begin{array}{l}3.9(0.3) \\
4 \cdot 1(0 \cdot 3) \\
3.30 \cdot 3)^{* *} \\
3.5(0.3)^{*}\end{array}$ & $\begin{array}{l}81(14) \\
84(14) \\
84(15) \\
87(15)\end{array}$ & $\begin{array}{l}0.34(0.09) \\
0.34(0.08) \\
0.39(0.10)^{* *} \\
0.39(0.10)^{* *}\end{array}$ & $\begin{array}{l}5.8(1.2) \\
5.7(1.1) \\
6.0(1.4) \\
6.3(1.8)\end{array}$ & $\begin{array}{l}0.95(0.30) \\
0.92(0.29) \\
0.97(0.32) \\
1.00(0.40)\end{array}$ & $\begin{array}{l}5 \cdot 2(0.7) \\
5 \cdot 2(0.8) \\
5 \cdot 4(0.9) \\
5 \cdot 5(1.0)\end{array}$ \\
\hline
\end{tabular}

Compared with placebo: ${ }^{*} \mathrm{p} \quad 0.01 ; * * \mathrm{p} .0 .0001$

+ Only 32 cases analysed. (HDL $=$ High density lipoprotein.

† Placebo values are averages of three periods.
Conrersion: SI to traditional wnits - Na : $1 \mathrm{mmol} 1-1 \mathrm{mEq} / 1 . \mathrm{K}: 1 \mathrm{mmol} / 1=1 \mathrm{mEq} / \mathrm{l}$. C.reatinine: $1: 2 \mathrm{~mol} / 1=0.01 \mathrm{mg} / 100 \mathrm{ml}$. Urate: $1 \mathrm{mmol}$ l $=16.8 \mathrm{mg} / 100 \mathrm{ml}$. Cholesterol and $\mathrm{HDL}$ cholesterol: $1 \mathrm{mmol} 1=38.6 \mathrm{mg} 100 \mathrm{ml}$

diuretic was disappointing-particularly since the patients were counselled at weekly intervals by the dietitian, which is unlikely to occur in daily practice. The fall in blood pressure with the $\beta$ blocker was substantially larger in the sodium restricted group than in the normal diet group. The $p$ values associated with the differences were sufficiently small virtually to rule out a chance finding, even when multiplicity-that is, the inflationary effects on the $p$ values of multiple testing - is taken into account.

Our data suggest that moderate sodium restriction is effective for the treatment of raised blood pressure when combined with a if blocker such as metoprolol. Treatment with this drug in the sodium restricted group appeared as effective as treatment with the metoprolol-chlorthalidone combination in the normal diet group and seems preferable, as the possible side effects of diuretic treatment, particularly hypokalaemia, are avoided. For the patients who did not restrict their salt intake no advantage could be detected for $25 \mathrm{mg}$ chlorthalidone as compared with $200 \mathrm{mg}$ metoprolol with respect to blood pressure lowering effect.

We found a relation between both plasma renin activity and age and the difference in blood pressures recorded during chlorthalidone and metoprolol treatment. Hence these factors may be relevant when deciding which drug is the most appropriate for a given patient. The wide scatter of the values (figs 1,2), however, precludes accurate prediction of individual outcome of treatment.

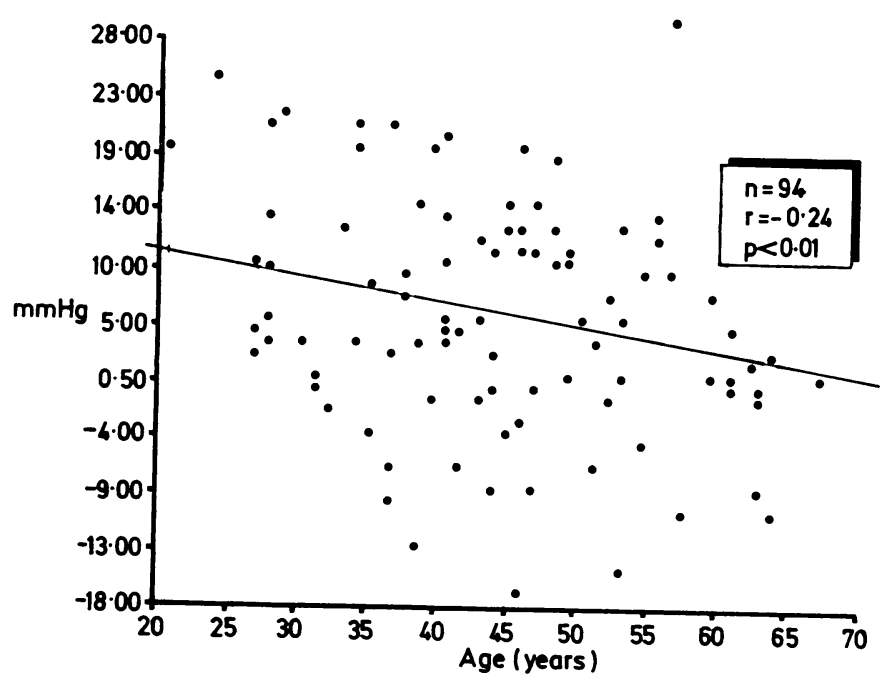

FIG 1-Supine diastolic blood pressure during chlorthalidone treatment minus supine diastolic blood pressure during metoprolol treatment plotted against age.

Moreover, the expected size of the reduction in blood pressure is not the only consideration when deciding treatment: tolerance and possible metabolic changes may play an important part. A rise in the serum concentrations of low density lipoprotein cholesterol, a decrease of high density lipoprotein cholesterol," the development of glucose intolerance,'15 and hypokalaemia,

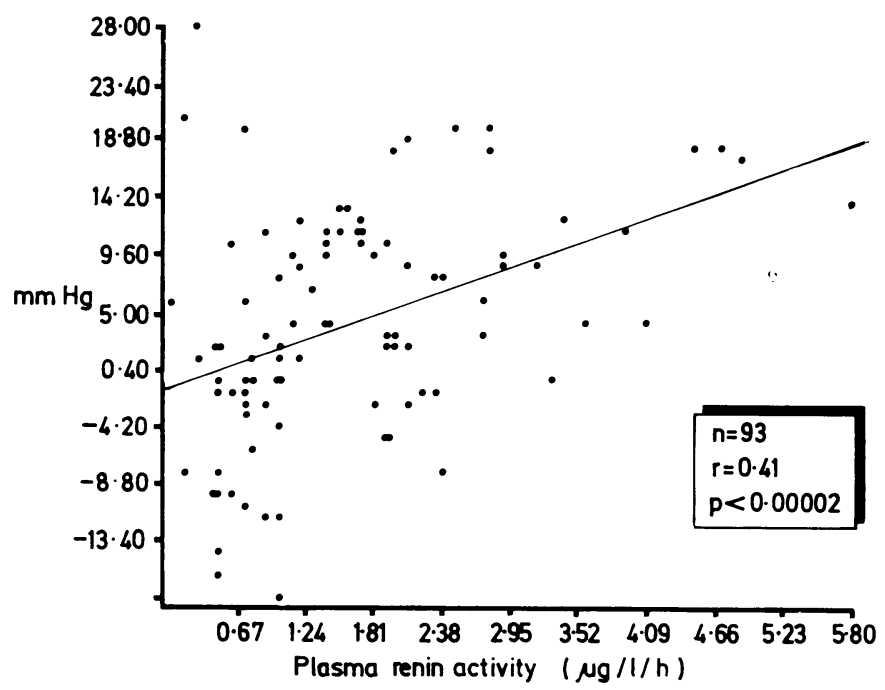

FIG 2-Supine diastolic blood pressure during chlorthalidone treatment minus supine diastolic blood pressure during metoprolol treatment plotted against plasma renin activity.

which has been implicated with arrhythmias and sudden death, ${ }^{11}$ may offset the beneficial effects of reduced blood pressure. In this respect our finding of a high incidence of hypokalaemia, even with this low dose of diuretic, is a cause of concern.

We thank Dr J Roos for help in the preparation of this study and Dr F M J Zuyderhoudt for his contribution in the lipid assay.

\section{References}

' Medical Research Council Working Party on Mild to Moderate Hypertension Adverse reactions to bendrofluazide and propranolol for the treatment of mild
hypertension. Lancet $1981 ;$ ii $: 539-43$. Kempner W. Treatment of hypertensive vascular disease with rice diet. Am $7 \mathrm{Med}$

' Parjis J, Joassens JV, Van der Linden L, Verstreken G. Moderate sodium restriction and diuretics in the treatment of hypertension. Am Heart 7 1973;85: 22-34.

- Simpson FO. Salt and hypertension: a sceptical review of the evidence. Clin Sc $1979 ; 57$ (suppl 5):463-80s.

Swales JD. Dietary salt and hypertension. Lancet 1980; i:1177-9.

Andrews G, MacMahon SW, Austin A, et al. Hypertension: comparison of drug and non-drug treatments. Br Med $\mathcal{F} 1982 ; 284: 1523-6$.

Watt GCM, Edwards C, Hart JT, Hart M, Walton P, Foy CJW. Dietary sodium restriction for mild hypertension in general practice. Br Med f 1983;286:432-6. low A , Locke C, Mitchell P, Humperson P. Evaluation of the effectiveness of a low sodium diet in the treatment of mild to moderate hypertension. Lance MacGregor GA.

over trial GA, Markandu ND, Bert FE, et al. Double-blind randomised crossover trial of moderate sodium restriction in essential hypertension. Lance

Van Brummelen $\mathbf{P}$, Schalekamp $\mathbf{M}$, de Graaff J Influence of scdium intake on hydrochlorothiazide induced changes in blood-pressure sodium intake on renin and aldosterone in essential hypertension. Acta Med Scand 1978;204:151-7. Wright BM, Dove CF. A random zero sphygmomanometer. Lancet $1970 ; 1: 337-8$ Duncan DB. Multiple range and multiple F-tests. Biometrics 1955;11:1-42:37Pickering G. Hypertension: causes, consequences and management. London: J \& A

' Ames RP, Hill P. Elevation of serum lipid levels during diuretic therapy of hypertension. Am F Med 1976;61:748-57.

globin and serum lipid concentrations after torance and lowering of glycohemoglobin and serum lipid concentrations after discontinuation of anti-hypertensive ' Hollifield JW' Siaton PE. Thiazide Acta Med Scand 1981;647:67-73.

(Acceptcd 24 May 1984) 